\title{
Time Concept Definition of Depth Space Theory
}

\author{
Yiming $\mathrm{Cai}^{1, \text { a }}$ \\ ${ }^{1}$ Adjunct Professor of School of Management, Zhejiang Ocean University, China; \\ Senior Economist of Zhoushan Port Authority, Zhejiang, China \\ a cym877@126.com
}

Keywords: resources, time concept, point, point circulation, point-to-point, definition, law, characteristics

\begin{abstract}
In the material world we live in, all the substances are all in a status of motion and circulation. There is a temporal definition and analysis between the utilization of energy and other resources by human and its influence on motion, circulation of substances and the environment. Based on such definition and analysis, we can see a different state of human's influence of resources utilization on environment at another level. The deep analysis and definition are made on depth space resources utilization at an angle of temporal dimension of energy and resources utilization.
\end{abstract}

\section{Time Concept Definition of Depth Space Theory}

There is no immobile substance in human's world and no motion of non-substance. The time concept of depth space theory is based on the theory of depth space and breadth space, $(1,2)$ Combined with modern scientific theories, the new time concept theories of "point", "point circulation" and "point-to-point circulation" of depth space resources are further put up academically.

Before talking about the time concept definition of depth space theory, the proposal of the theory of breadth space and depth space should be explained first.

Breadth and depth space theory of "ocean" development is a new geopolitical theory in domain of the social sciences. (2) Breadth space and depth space are defined as follows. We divide modern ocean in view of resources control scope, due to progress and development of society, control of renewable energy and resources can be included in resource control, which is not available in recent period. Judging from resources control, modern ocean can be further divided into breadth space and depth space, both of which have characteristic of "being unlimited". The so-called breadth of ocean space purely refers to ocean space. From microscopic space to the entire ocean space, all can be called as the breadth of ocean space. To some extent, ocean development can be understood as development toward space and outer space. It is also the development of "new ocean" space, therefore, breadth space also include the outer space. Breadth space is almost "unlimited". The so-called depth of ocean space refers to development of ocean wind energy, solar energy and other renewable energy and other resources. Since these renewable energies and resources are inexhaustible, then "depth" is unlimited. Therefore, depth development is almost "unlimited". Development and utilization of solar energy and other renewable resources in outer space in the future can be included in exploration of depth space.

Depth space resources do not only exist in ocean and "new ocean", wind energy, solar energy and other renewable resources on land are also very rich. Therefore, depth space resources also exist on land. In addition, recycling and re-use of scrap iron and steel, petrochemical products can also be regarded as exploration of depth space. Ocean depth space means the depth space of ocean and "new ocean", while depth space also included the depth space on land, in addition to that of ocean and "new ocean".

The time concept of depth space resources declares different states during different periods of depth space resources and brings in the understandings of time concept during resources' utilization, including an analysis and definition with time concept under circulation state of energy and other resources. The "point" time concept of depth space resources refers to the momentary work and extension of solar energy and other energies at one point. While the concept of "point circulation", 
refers to that of plant resources. And this time concept covers a reasonable period of influences on the living environment by human's utilization of plant resources. The time concept of "point-to-point" resource circulation refers to human society's recycling of scrap steel, waste glass and other renewable resources.

\section{Time Concept of Point}

The time concept of depth space resources point is direct and fast.

It is easy to understand about the work and utilization at one point of depth space energy and other resources which utilizes naturally produced energy in natural world and maintains natural ecology.

The most direct utilization of depth space resources is the direct work and utilization at one point, for example, the wind energy reception and utilization for electricity generation at a fixed point of vertical-axis wind turbine. (Figure 1)

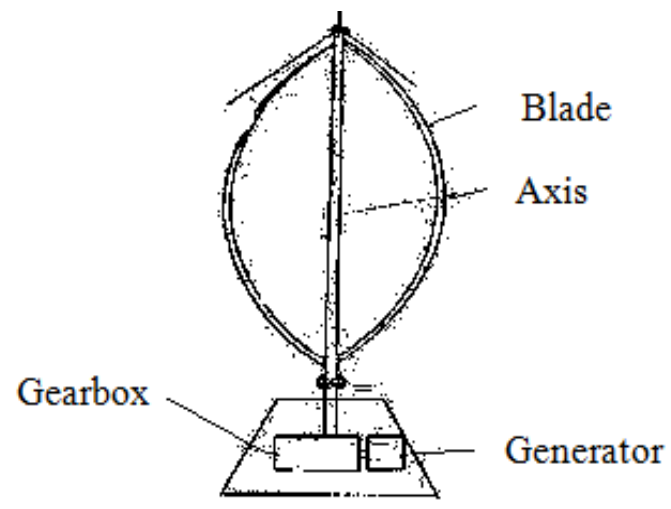

Fig. 1 Ф-type wind energy turbine

Fig. 1: The types of vertical-axis wind turbine include $\Phi$-type, S-type, H-type and so on. There are more and more studies on it and all kinds of new wind turbines are coming in all the time. Though the vertical-axis wind turbine has not been commercialized, it has characteristics such as suitable for installation on land, convenient, maintenance, free of huge tower, simple blade manufacture, etc.

The time concept of depth space resources point is to utilize the energy generated by natural world to work directly which is most direct, fastest and cleanest.

In modern science, energies come from outside of the Earth are usually called external energies which mainly include solar radiation energy, potential energy, tidal energy, bio-energy and so on. Energies come from inside of the Earth are called internal energies which mainly include thermal energy inside the Earth, gravitational energy, energy of the Earth rotation, chemical energy and crystallization energy.

According to the studies on external and internal energy resources of the Earth of modern science, we can learn the ins and outs of depth space resources observe that depth space resources are the energies naturally generated during substances circulating motion on the Earth and have a deeper understanding and recognition of the nature of depth space resources.

External Energies of the Earth mainly refer to solar radiation and others.

Solar radiation is the heat and energy transmitted from the Sun to the Earth. $60 \%$ of the solar radiation is absorbed by atmosphere, land and oceans, turning into the major energy for the activities, growth, exchange of substances and energies among atmosphere, hydrosphere and biosphere. And it leads to a series of exogenic forces such as wind, running water, glacier, waves and so on.

Tide energy is the energy generated by the changing gravitation on points of whirling Earth by the Sun and the Moon. Under its influence, tidal phenomenon occurs in the oceans on Earth. Tide holds mechanical energy. 
There is heat on the Earth's surface brought by cosmic rays of outer space, chemical reaction and crystallization.

Thermal energy inside the Earth mainly comes from radioactive and gravitational heat conversion. Radioactive heat is generated by the transformation of radioactive elements inside the Earth. While the heat generated by gravitational differentiation is that released and converted by potential energy during differentiation progress of Earth's substances under influence of gravity.

Gravitational energy is objects' potential energy brought by Gravity. Earth's rotation energy is the energy given to substances on Earth's surface which is generated by Earth's rotation. It includes centrifugal force, pole-fleeing force and coriolis' force.

Utilization of the energy on one "point" which is naturally generated during substances circulation on Earth belongs to "point" work and extension of depth space resources in nature.

\section{Time Concept of Point Circulation}

The time concept of point circulation by plant depth space resources refers to the circulation time process of absorption, utilization and release via production of human, and re-absorption and release of carbon dioxide and other chemical substances during lifetime of plant resources. The absorption of harmful gases and release of chemical substances are nearly the same during absorption and release progress of plant resources, which maintains the ecological balance of the natural world and has little impact on human's living environment and nature. The time concept of point circulation of plant resources includes energy-plant point circulation other point circulation types.

Natural and geographical environment is composed of atmosphere, water, creatures, rocks, soil and other geographical elements. These elements conduct energy exchange and movements among substances through atmosphere circulation, water circulation, biological circulation, lithosphere circulation, etc. They neither simply flock together nor occasionally gather in space but form a whole body of mutual penetration, restraint and interconnection.

During the point circulation of plant resources, energy and other resources plant turn inorganic substances by photosynthesis into organic substances and then carry them from inorganic environment to plant. Through human's extraction and processing of energy plant and then through decomposition and release in natural world, organic substance will turn into inorganic substance. The work and utilization of plant and other resources point in depth space have little influence on natural environment or just have influence over a reasonable period, after which it will return to natural status.

1. The Time Concept of "Point Circulation" of Energy Plants (Figure 2)

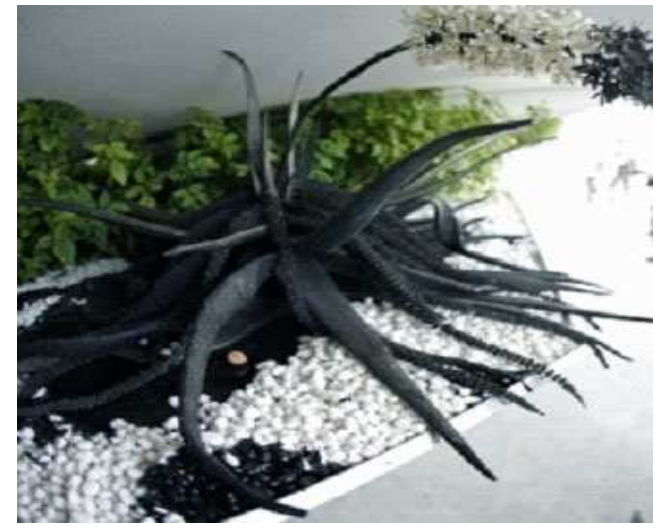

Fig. 2: "Future plant can become petroleum" displayed in UK Pavilion during Shanghai EXPO. (3)

The process from growth to utilization of "point" resources of energy plant is the process from absorption to release of carbon and other substances. The time sequence of point utilization is first absorption, then release. Experts calculate that it take 20 30 years from (growth) absorption to (utilization) release and then back to atmosphere. Resources utilization of energy plant's "point" 
circulation, referring to circulation time and reasonable scale, maintains the basic balance of substances circulation in natural world and has little influence on human living environment and nature.

2. The Time Concept of "Point Circulation" of Mental Resource Plant

Except for absorption of energy, plants also can absorb mental and other resources.

It is reported that Meigeliete, a biologist of the University of Oldenburg, Russia unexpectedly found that leaves contain an unusually high volume of zinc, lead, cadmium and other metals when he studied an annual herb called smartweed in 1995. He planted a large number of smartweed in some lands polluted by zinc, lead, cadmium and other metals. In result, he got a harvest on one hectare land in the first season. That smartweed flourished with big and thick leaves. Meigeliete put smartweed grass into an $800^{\circ} \mathrm{C}$ oven and got $1.3 \mathrm{~kg}$ cadmium, $23 \mathrm{~kg}$ lead and $322 \mathrm{~kg}$ zinc, while the grass burnt into ashes. His study aroused interests of relevant German departments. Various military exercise fields left in German history, including warehouses keeping chemical weapons during Second World War. In order to eliminate soil mental pollution and reform environment, a research group of Alden University in Germany had succeeded in introducing Russian smartweed to a discarded mental yard. To popularize this research result, the group even set up a commercial company and it has received a large number of orders from all parts of Germany, especially environment protection organization.

Recently, there was literature reported that experts from California, USA found out via research that wild mustard has a function to collect nickel from soil. They cut half hectare of wild mustard rods they planted, dried and burned to ashes. 15 20 gram nickel was extracted from every 100 gram ashes. Scientific researches show that during million years' evolution, plants have trained to some tricks. Many plants have abilities to collect specific mental elements, for example, if we plant corn or scouring rush in lands containing much gold, and burn them into ashes, we can get 10 gram gold out of one ton ashes. Violet' collecting ability of zinc, elsholtzia's collecting ability of copper, tobacco's collecting ability of uranium, milk vetch's collecting ability of selenium, alfalfa's collecting ability of tantalum, and club moss' collecting ability of manganese is incomparably high. Wild mustard has function to store nickel from soil. (4)

3. Time Concept of "Point Resources" of Other Resources

Crops belong to the depth space of human point's chemical circulation which we are very familiar with. People have different crop planting histories. According to relevant materials, south-east Asia began around 6800-4000 BC; Near-East and Europe began around 6500-3500 BC; Central America and Peru began about $2500 \mathrm{BC}$.

Crops refer to species natured and planted in agricultural production in general. They are classified as "grain crops", "cash crop", etc. While in view of utilization direction, they can be classified as "fiber", "starch", "sugar", "beverage", "rubber", "dye", "herb", "aromatic oil crop", etc. Grain crops mainly include rice, wheat, corn, bean, potato, broad bean and so on; cash crops mainly include oilseed, flax, sunflower, etc; vegetable crops mainly include green vegetables, turnip, celery, leek, carrot, day-lily, chili, tomato and so on.

\section{Time Concept of point-to-point Resources Circulation}

The time concept of point-to-point resources circulation in depth space refers to, during human's utilization of renewable resources (scrap steel, waste glass, etc), take advantage of recycling of renewable resources to reduce resources consumption and energy consumption and try to control the emission of $\mathrm{CO} 2$ and other harmful gases and substances within a reasonable recycling time which has no influence or little influence on human's life and natural environment.

\section{The Formula and Law of Depth Space Resource "Point" and "Point Circulation"}

The Formula and Law of Depth Space Resource "Point" and "Point Circulation" (5):

Formula 1: N stands for natural world

D 1 stands for solar energy and other depth space resources

$\triangle 1$ stands for the work and extension at one point 


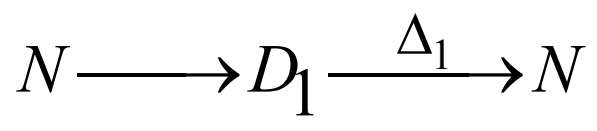

In words, this formula can be expressed as follows: $\mathrm{N}$ stands for natural world; $\mathrm{D} 1 \mathrm{stands}$ for solar energy and other depth space resources; $\triangle_{1}$ stands for, under natural conditions, energy produced in nature directly work and extend at one point, after work at one point $\mathrm{N}$ returns to natural condition quickly. From $\mathrm{N}$ to $\mathrm{N}$, after work at point $\mathrm{D}_{1}$, relation between ecology is balanced.

It can also be expressed by law. The law 1 applied by depth space resources is to use the energy generated in natural world to work and extend at one point directly but does not change substance structure of natural nature of working energy.

Formula and Law of Point-to-point Plant Resource: (5)

Formula 2: $\mathrm{N}$ stands for the natural world before resource utilization

$\mathrm{D}_{2}$ stands for algae and other productive depth space resources

$\triangle 2$ stands for the reasonable time period of work

$\mathrm{N}_{2}$ stands for the natural world after resources recovery from utilization

$$
N \longrightarrow D_{2} \stackrel{\Delta_{2}}{\longrightarrow} N_{2}
$$

$\mathrm{N}$ stands for natural world, from plant resources utilization D2 to chemical work of resources utilization $\Delta 2$ and after the reasonable time period of point circulation recovery, obtain a balance between nature and ecology. Therefore, the relation is balanced from $\mathrm{N}$ to $\mathrm{N} 2$ eventually.

The law 2 of depth space resources utilization is: use the work and extension of resources "point" and then after a reasonable time period of resources "point" circulation recovery, obtain the balance between resources utilization and natural ecology.

For discovery and proposal of energy and resources depth space laws, the most convincing argument is that utilization of depth space energy and other resources during work and extension at one point does not change or slightly affects natural environment which has no chemical-structure influence on natural environment or just has influence for a reasonable time period, after which it will return to natural condition.

\section{Characteristics Description of Stage Definition and Division of Depth Space Resources Utilization}

During utilization process of energy and other resources, human can divide it into several stages with characteristics description as follows:

1. Utilization Stage of Depth Space Energy and Other Resources.

The combined contents of utilization stage period of depth space energy and other resources have time concepts of "point", "point circulation" of plant resources and "point-to-point" circulation. Their key characteristics are as follows. During process of energy and other resources progress, under natural conditions, use the energy generated by natural world to work and extend directly at one point; maintain ecological balance; while the time concept of plant point circulation and that of point-to-point resources circulation are based on the reasonable time period during which circulation process leave no negative influence on human life and natural world, as well as on the premise that energy and other resources circulation has no negative influence on human life and natural world.

2. Defining Characteristics of Working Time Range at One Point.

For the working time range at one point, defining characteristics of time concepts of plant point circulation and point-to-point circulation are as follows. Firstly, use natural energy to work directly, leaving no influence on environment. Secondly, circulation progress from work back to nature should have no influence on human's living environment or just very little influence. 


\section{Acknowledgments:}

I appreciate this good chance for me to exchange my academic views about the law how human utilize resources and discuss our common concern with experts and scholars. Therefore, I'd like to take this opportunity to thank Professor Xu Jianhua, Professor Lv Bingquan, Mr CaoYunhong and Mr Luo Jiajia for their kind support and help in English translation. I could take the complete responsibility for the academic views and formula I proposed.

\section{References and Notes}

[1] Yiming Cai. Depth Space and the Theory of Depth Space Control Power, Advanced Materials Research Vols. 361-363. 2012. C (2012) Trans Tech Publications, Switzerland: 895-905.

[2] Yiming CAI, On Breadth and Depth Space for "Ocean Development” [J]. TELOS - Special Edition in Honour of Guido de Marco@ Fondation de Malte. Volume V, 2011:111-130.

[3] http://www.anhuinews.com/zhuyeguanli/system/2010/05/03/002864222_10.shtml

[4] http://chongqing.favolist.com/22320382.shtml.

[5] Yiming Cai. Material Form and Nature of Depth Space Resources, [J]Advanced Materials Research Vols. 524-527 (2012). C (2012) Trans Tech Publications, Switzerland: pp 3398-3402. 